\title{
Inibição da ação do etileno e temperatura de armazenamento no padrão de amadurecimento de tomates
}

\author{
Ethylene action inhibition and storage temperature on the tomatoes ripening patterns
}

\author{
Auri Brackmann ${ }^{*}$ Ricardo Fabiano Hettwer Giehl ${ }^{\text {II }}$ Ana Cristina Eisermann ${ }^{\text {II }}$ \\ Anderson Weber ${ }^{\mathrm{I}}$ Arno Bernardo Heldwein ${ }^{\mathrm{I}}$
}

\section{RESUMO}

O objetivo deste trabalho foi avaliar o efeito da inibição da ação do etileno sobre o amadurecimento e o desenvolvimento de dano causado pelo frio em tomates do tipo não longa vida da cultivar 'Monte Carlo'. O experimento foi conduzindo no delineamento inteiramente casualizado, em esquema fatorial (3x2), com quatro repetições. O Fator A foi composto por temperaturas de armazenamento $\left(20^{\circ} \mathrm{C}, 10^{\circ} \mathrm{Ce}\right.$ $\left.5^{\circ} \mathrm{C}\right)$, já o Fator $B$ foi composto pela aplicação ou não de 1,0 $\mu \mathrm{L} \mathrm{L}^{-1}$ de 1-metilciclopropeno (1-MCP), um composto que bloqueia a ação do etileno. Depois de 14 dias de armazenamento, verificaram-se dois padrões distintos de amadurecimento dependentes da temperatura de armazenamento. A temperatura de $5^{\circ} \mathrm{C}$ levou ao desenvolvimento de dano pelo frio, o que resultou em elevada produção de etileno sem, contudo, levar a alterações significativas no amadurecimento dos frutos. Esses resultados indicam que sob essa temperatura os frutos perdem a sensibilidade ao etileno. No entanto, sob temperaturas acima do limite de dano, a aplicação de 1-MCP não apenas reduziu a sintese de etileno, mas também inibiu o amadurecimento, sendo a duração desse efeito maior a $10^{\circ} \mathrm{C}$ do que a $20^{\circ} \mathrm{C}$. A qualidade de tomates não longa vida pode ser mantida por até 14 dias com o armazenamento a $10^{\circ} \mathrm{C}$ ou com a aplicação de 1-MCP a $20^{\circ} \mathrm{C}$.

\section{Palavras-chave: Lycopersicum esculentum, 1- metilciclopropeno, dano pelo frio, qualidade pós-colheita.}

\section{ABSTRACT}

This research aimed to evaluate the effect of inhibiting the ethylene action on the ripening and on the development of chilling injury in non-long life 'Monte Carlo' tomatoes. The experiment was a fatorial (3x2), with storage temperature $\left(20^{\circ} \mathrm{C}, 10^{\circ} \mathrm{C}\right.$ and $\left.5^{\circ} \mathrm{C}\right)$ and the treatment or not of
1.0 $\mu \mathrm{L} L^{-1}$ of 1-methylcyclopropene (1-MCP), a compound that blocks the ethylene action. After 14 days of storage, two distinct patterns of ripening dependents on the storage temperature were observed. The storage under $5^{\circ} \mathrm{C}$ led the fruits to develop chilling injury (CI). Although CI-affected fruits showed higher ethylene production, they did not ripen properly, suggesting that CI results in a lack of ethylene sensitivity in tomatoes. On the other hand, above chilling temperatures, 1-MCP treatment not only reduced the ethylene synthesis, but also inhibited the ripening process. The inhibitory effect of 1-MCP was, however, significantly longer at $10^{\circ} \mathrm{C}$ as compared to $20^{\circ} \mathrm{C}$. The quality of non-long-life tomato fruits can be maintained during 14 days either by storing at $10^{\circ} \mathrm{C}$ or by applying 1-MCP at $20^{\circ} \mathrm{C}$.

Key words: Lycopersicum esculentum, 1-methylcyclopropene, chilling injury, postharvest quality.

\section{INTRODUÇÃo}

Tomates são classificados como frutos climatéricos, pois apresentam um pico respiratório concomitante ao aumento na síntese de etileno. Esse processo determina o início do processo de amadurecimento, que resulta em alterações na coloração, no aroma, na textura, no sabor e em outros atributos bioquímicos e fisiológicos dos frutos (ALEXANDER \& GRIERSON, 2002). Em função disso, tomates apresentam uma curta vida pós-colheita, o que pode ocasionar perdas significativas durante os processos de transporte e comercialização.

Apesar de a frigoconservação ser uma prática comumente utilizada para retardar o

'Departamento de Fitotecnia, Universidade Federal de Santa Maria (UFSM), 97105-900, Santa Maria, RS, Brasil. E-mail: brackman@ccr.ufsm.br. *Autor para correspondência.

IIInstitut für Pflanzenernährung, Universität Hohenheim, Stuttgart, Alemanha. 
amadurecimento de frutos e hortaliças, sob condições inadequadas, pode causar danos decorrentes da exposição a baixas temperaturas. A severidade desses danos depende da duração da exposição e da temperatura abaixo do limite aproximado de $12^{\circ} \mathrm{C}$ (SALTVEIT, 2001). O dano por frio resulta em amadurecimento anormal, escurecimento da casca, elevada incidência de podridões e maior permeabilidade das membranas celulares (MORRIS, 1982; SALTVEIT, 2005; MALACRIDA et al., 2006). No caso de tomates, a sensibilidade dos frutos aos danos causados pelo frio depende, tanto do estádio de desenvolvimento e da cultivar, quanto do tempo de exposição a essas temperaturas (HOBSON \& GRIERSON, 1993).

As evidências sobre o efeito do etileno sobre o desenvolvimento de danos pelo frio são controversas. O desenvolvimento de tolerância a baixas temperaturas em plântulas de tomateiro (CIARDI et al., 1997) e em frutos cítricos (LAFUENTE et al., 2001) foi relacionado a um aumento na síntese de etileno. Por outro lado, em melões, a inibição da síntese e/ou da ação do etileno pode prevenir o desenvolvimento de danos por frio (BEN-AMOR et al., 1999).

Portanto, o objetivo deste trabalho foi avaliar o efeito de 1-metilciclopropeno (1-MCP) sobre o amadurecimento e o desenvolvimento de danos pelo frio em tomates do tipo não longa vida.

\section{MATERIAL E MÉTODOS}

O experimento foi conduzido no Núcleo de Pesquisa em Pós-colheita (NPP), em conjunto com o Setor de Agroclimatologia, ambos do Departamento de Fitotecnia da Universidade Federal de Santa Maria (UFSM), Santa Maria, Brasil. A cultivar utilizada foi a 'Monte Carlo', não longa vida, que produz frutos multiloculares, apreciados pela sua coloração e pelo sabor pronunciados. Os frutos foram colhidos quando apresentavam cerca de $10 \%$ de cobertura vermelha na casca, conforme recomendado por HOBSON \& GRIERSON(1993).

Logo após a colheita, os frutos foram selecionados e as amostras formadas e homogeneizadas. As unidades experimentais foram compostas por 10 frutos. O experimento foi conduzindo no delineamento inteiramente casualizado e em esquema fatorial $(3 \times 2)$, com quatro repetições. O Fator A foi constituído por diferentes temperaturas de armazenamento $\left(20^{\circ} \mathrm{C}, 10^{\circ} \mathrm{C}\right.$ e $\left.5^{\circ} \mathrm{C}\right)$, já o Fator $\mathrm{B}$ foi constituído pela aplicação ou não de 1metilciclopropeno (1-MCP), na concentração de $1,0 \mu \mathrm{L}$ $\mathrm{L}^{-1}$ de ar da câmara de armazenamento.
A aplicação de 1-MCP foi efetuada durante 24 horas na temperatura de armazenamento. A quantidade calculada de 1-MCP necessária para atingir as concentrações preestabelecidas foi colocada em recipientes de vidro com $50 \mathrm{~mL}$ de volume, os quais foram vedados. Adicionou-se água em temperatura ambiente $\left(15 \mathrm{~mL}\right.$ de água $\mathrm{g}^{-1}$ de produto), sendo os recipientes vigorosamente agitados até o desaparecimento completo da turbidez. Os recipientes foram, então, colocados no interior das mini-câmaras com sistema de ventilação fechado. Os frascos foram abertos, liberando-se o 1-MCP, sendo as mini-câmaras imediatamente vedadas. Essas condições foram mantidas durante 24 horas, quando a composição gasosa das mini-câmaras foi totalmente eliminada, sendo renovada por ar natural. Como fonte de 1-MCP, utilizou-se o produto comercial SmartFresh ${ }^{\mathrm{TM}}$ (Rohm \& Haas Co.) na formulação pó ( $0,14 \%$ i.a.).

As temperaturas das câmaras de armazenamento foram reguladas por termostatos eletrônicos e monitoradas diariamente por meio de termômetros de mercúrio com $0,1^{\circ} \mathrm{C}$ de resolução, inseridos na polpa de frutos. A umidade relativa do ar no interior das mini-câmaras foi mantida em $94 \pm 2 \%$ durante todo o período de armazenamento.

Após 14 dias de armazenamento, foram avaliados a síntese de etileno, a respiração, o desenvolvimento da coloração da casca e a ocorrência de danos pelo frio durante quatro dias de amadurecimento a $20^{\circ} \mathrm{C}$. No quarto dia, foram determinados também a firmeza da polpa, a acidez titulável, os teores de sólidos solúveis totais, a cor de fundo da polpa e a incidência de podridões. Além disso, a cobertura vermelha dos frutos foi determinada visualmente por meio de índices de coloração, em que índice $0=<10 \%$ da superfície coberta com coloração vermelha; $1=11$ a $20 \% ; 2=21$ a $40 \% ; 3=41$ a $60 \% ; 4=61$ a $80 \%$; e $5=>80 \%$. Para a determinação do índice de escurecimento da casca, considerou-se: $1=<10 \%$ da casca escurecida; $2=10$ a $20 \%$; $3=21$ a $30 \%$; e $4=>30 \%$. $\mathrm{O}$ índice de cada amostra foi calculado utilizando-se a seguinte fórmula: Índice da amostra $=[\Sigma$ (índice $)\left(\mathrm{n}^{\mathrm{o}} \mathrm{de}\right.$ frutos naquele índice) / $\mathrm{n}^{\mathrm{o}}$ total de frutos da amostra].

A síntese de etileno foi determinada utilizando-se um cromatógrafo a gás Varian ${ }^{\circledR}$, modelo CX3400, equipado com um detector FID e uma coluna de aço inox de 1/8" e 2,00m de comprimento, preenchida com Porapak ${ }^{\circledR}$ N. As temperaturas da câmara de injeção, do detector e da coluna foram programadas em $90^{\circ} \mathrm{C}$, $120^{\circ} \mathrm{C}$ e $240^{\circ} \mathrm{C}$, respectivamente. As amostras, compostas de seis frutos cada, foram colocadas em recipientes de vidro com 51 , fechados de forma hermética e acondicionados a $20 \pm 1{ }^{\circ} \mathrm{C}$ durante cerca de uma hora. 
Depois de transcorrido esse período, foram retiradas duas amostras de $1 \mathrm{~mL}$ do gás contido em cada recipiente, sendo estas injetadas diretamente no cromatógrafo. Os resultados foram expressos em $\mu \mathrm{L}$ $\mathrm{C}_{2} \mathrm{H}_{4} \mathrm{~kg}^{-1} \mathrm{~h}^{-1}$. A respiração foi determinada pela circulação do conteúdo dos recipientes por meio de um analisador de fluxo contínuo, da marca Agridatalog ${ }^{\circledR}$. Os dados foram expressos em $\mathrm{mL} \mathrm{CO}_{2}$ $\mathrm{kg}^{-1} \mathrm{~h}^{-1}$. A cor de fundo da polpa foi analisada com o auxílio de um colorímetro Minolta ${ }^{\circledR}$, modelo CR-310, usando o sistema CIE L*a*b*. Os valores foram convertidos em ângulo de cor $\left({ }^{\circ} \mathrm{h}\right)$, em que ${ }^{\circ} \mathrm{h}=$ arco tangente $\left(\mathrm{b}^{*} / \mathrm{a}^{*}\right)$. A firmeza da polpa $(\mathrm{N})$ foi determinada utilizando-se um penetrômetro manual com ponteira de 11,0mm de diâmetro, sendo efetuada em dois pontos opostos sobre a região equatorial dos frutos. Os sólidos solúveis totais (SST) foram obtidos por meio de um refratômetro manual com correção da temperatura. A acidez titulável foi obtida pela titulação com $\mathrm{NaOH} 0,1 \mathrm{~N}$ de uma solução contendo $10 \mathrm{~mL}$ de suco diluídos em $100 \mathrm{~mL}$ de água destilada até atingir-se $\mathrm{pH} 8,1$. Os resultados foram expressos em meq $100 \mathrm{~mL}^{-1}$.

Os dados com distribuição normal foram submetidos à análise da variância. Os dados expressos em porcentagem, originalmente distribuídos binomialmente, foram, previamente à análise da variância, transformados pela equação $\mathrm{f}(\mathrm{x})=$ arco seno $(\mathrm{x} / 100)^{1 / 2}$ para serem normalizados. As médias foram comparadas pelo teste de Duncan $(\mathrm{P} \leq 0,05)$.

\section{RESULTADOS E DISCUSSÃO}

Após 14 dias de armazenamento, os frutos armazenados a $5^{\circ} \mathrm{C}$ apresentaram maior produção de etileno, e a aplicação do inibidor de etileno 1-MCP resultou em produção mais elevada de etileno em comparação com os frutos sem o produto (Figura 1A). A aplicação de 1-MCP, no entanto, reduziu a produção de etileno nos frutos armazenados a $20^{\circ} \mathrm{C}$ e, especialmente, $\mathrm{a} 10^{\circ} \mathrm{C}$. Pesquisas têm demonstrado que a síntese de etileno em tomates tratados com 1-MCP mantém-se baixa por períodos que duram de oito a 15 dias, dependendo do estádio de maturação em que os frutos são colhidos (HOEBERICHTS et al., 2002). Todavia, os resultados do presente trabalho demonstram que os efeitos desse composto sobre a produção de etileno são dependentes também da temperatura de armazenamento. Os frutos armazenados a $5^{\circ} \mathrm{C}$ apresentaram maior atividade respiratória, durante a exposição pós-armazenamento a $20^{\circ} \mathrm{C}$ (Figura 1B). Além disso, a inibição da ação do etileno também estimulou a atividade respiratória desses frutos a $5^{\circ} \mathrm{C}$.

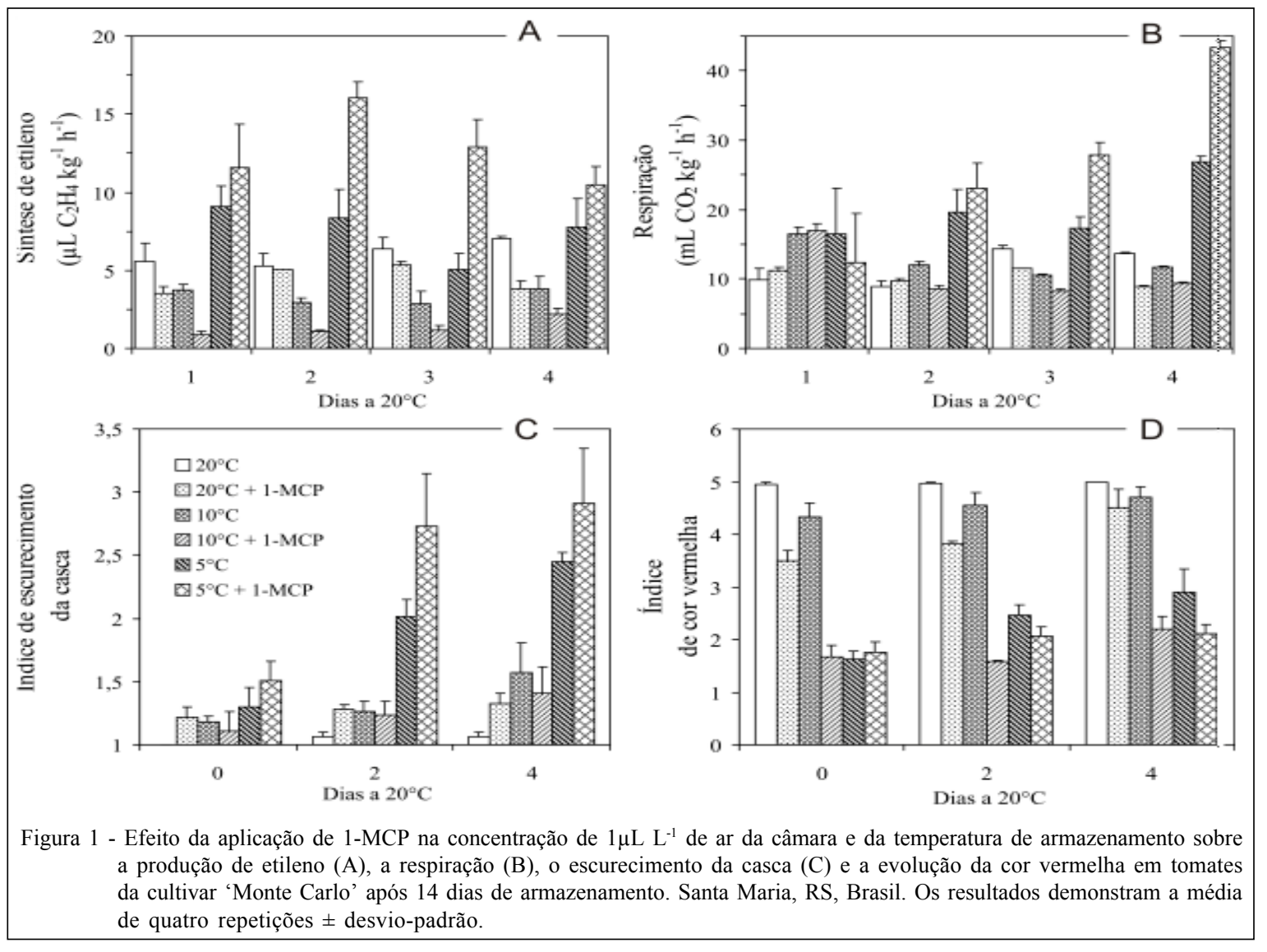

Ciência Rural, v.39, n.6, set, 2009. 
Os resultados deste trabalho (Figura $1 \mathrm{~A}$ e B) demonstram que a inibição da ação do etileno estimula ainda mais o desenvolvimento dos danos por frio a $5^{\circ} \mathrm{C}$, visto que os aumentos da síntese de etileno e da respiração após o armazenamento de frutos sob baixas temperaturas são sintomas típicos de danos pelo frio (MORRIS, 1982; MALACRIDA et al., 2006).

$\mathrm{O}$ armazenamento dos frutos a $5^{\circ} \mathrm{C}$ resultou em maior escurecimento da casca, o que foi agravado levemente com a aplicação de 1-MCP (Figura 1C). O escurecimento da casca também tem sido reconhecido como um sintoma de dano pelo frio (MORRIS, 1982). Sob baixas temperaturas ocorrem alterações na estrutura e composição das membranas, o que reduz o controle da permeabilidade destas (SALTVEIT, 2005; MALACRIDA et al., 2006) e, possivelmente, resulta em disfunções metabólicas. Interessantemente, o escurecimento dos frutos armazenados a $5^{\circ} \mathrm{C}$ aumentou drasticamente durante o período de exposição a $20^{\circ} \mathrm{C}$. Segundo MORRIS (1982), os sintomas de dano por frio geralmente desenvolvem-se quando os frutos são transferidos para temperaturas mais elevadas. Esse resultado poderia estar ligado, aparentemente, ao rápido incremento da produção de etileno e especialmente da respiração. A respiração é responsável pelo aumento pós-armazenamento de espécies reativas de oxigênio (JIMENEZ et al., 2002; MALACRIDA et al., 2006), as quais ocasionam, entre outras, a peroxidação lipídica e a consequente redução da permeabilidade das membranas (MONTILLET et al., 2005).

O índice de coloração vermelha da casca, que estima subjetivamente a concentração de carotenóides na casca e relaciona-se ao amadurecimento dos frutos (BRANDT et al., 2005; MALACRIDA et al., 2006), foi influenciado pelas condições avaliadas (Figura 1D). O 1-MCP reduziu o índice de cobertura vermelha, sendo esse efeito mais drástico nos frutos armazenados a $10^{\circ} \mathrm{C}$, demonstrando o efeito desse composto sobre o amadurecimento (Figura 1D). A cor de fundo da epiderme dos frutos tratados com 1-MCP estava mais verde, como demonstram os maiores valores de ângulo de cor $\left({ }^{\circ} \mathrm{h}\right)$ determinados em ambas as avaliações (Figuras $2 \mathrm{~A} \mathrm{e}$ B). Resultados semelhantes foram reportados por HOEBERICHTS et al. (2002) também em tomates tratados com 1-MCP. Os frutos armazenados a $5^{\circ} \mathrm{C}$ apresentaram um aumento limitado na coloração vermelha e na degradação da cor verde, mesmo quando a ação do etileno não foi bloqueada (Figuras 1D, 2A e B). Baixas temperaturas afetam negativamente os conteúdos de carotenóides, em especial de licopeno, em tomates (MALACRIDA et al., 2006). As respostas dependentes de etileno são desencadeadas quando este fito-hormônio liga-se aos seus receptores (TIEMAN et al., 2000). Dessa forma, considerando a elevada produção de etileno dos frutos armazenados a $5^{\circ} \mathrm{C}$ (Figura 1A), a manutenção da inibição da evolução da cor desses frutos após o armazenamento (Figura 1D) indica que a ligação do etileno aos receptores e/ou a transdução do sinal são dramaticamente afetadas sob essa temperatura. Isso poderia indicar que os danos causados pelo frio resultam numa perda de sincronia entre os vários eventos fisiológicos e bioquímicos relacionados ao amadurecimento.

O bloqueio da ação do etileno manteve os frutos armazenados a $20^{\circ} \mathrm{C} \mathrm{e} 10^{\circ} \mathrm{C}$ mais firmes (Figura 2C). Como o etileno estimula a expressão e a ação de várias enzimas hidrolíticas da parede celular, como as poligalacturonases (SITRIT \& BENNETT, 1998) e as expansinas (ROSE et al., 1997), a inibição da sua ação possivelmente reduziu a degradação das paredes celulares e, consequentemente, a perda da firmeza da polpa. Todavia, o 1-MCP não afetou a firmeza da polpa dos frutos armazenados a $5^{\circ} \mathrm{C}$ (Figura 2C).

A aplicação de 1-MCP reduziu os valores de SST/AT quando os frutos foram armazenados sob $20^{\circ} \mathrm{C}$ e $10^{\circ} \mathrm{C}$ (Figura 3A), concordando com os resultados de GUILLÉN et al. (2007). No entanto, sob $5^{\circ} \mathrm{C}$ não houve diferença significativa para esse parâmetro. A ação do etileno afetou os níveis de acidez titulável dos frutos armazenados a $20^{\circ} \mathrm{C} \mathrm{e} 10^{\circ} \mathrm{C}$, e o uso de 1-MCP manteve esses níveis mais elevados (Figura 3B). Tomates tratados com 1-MCP apresentam pequena alteração na acidez titulável (WILLS \& KU, 2002). A elevada taxa respiratória pós-armazenamento dos frutos submetidos a $5^{\circ} \mathrm{C}$ (Figura $1 \mathrm{~B}$ ) resultou em níveis de acidez titulável iguais àqueles dos frutos mantidos durante todo o período a $20^{\circ} \mathrm{C}$ sem 1-MCP (Figura 3B). A incidência de podridões foi menor nos frutos armazenados a $10^{\circ} \mathrm{C}$, e a aplicação de 1-MCP foi eficiente na redução da ocorrência de podridões nos frutos armazenados a $20^{\circ} \mathrm{C}$ (Figura $3 \mathrm{C}$ ), provavelmente por retardar o amadurecimento. A elevada incidência de podridões nos frutos armazenados a $5^{\circ} \mathrm{C}$ (Figura 3C) confirma que os danos causados pelo frio aumentam a susceptibilidade dos frutos a patógenos (MORRIS, 1982). Além disso, sob $20^{\circ} \mathrm{C}$ cerca de $70 \%$ dos frutos apresentaram podridões, e a aplicação de 1MCP reduziu esses valores para aproximadamente $20 \%$ (Figura 3C).

A comparação entre os frutos armazenados a $10^{\circ} \mathrm{C}$ e $5^{\circ} \mathrm{C}$ permite identificar dois padrões de amadurecimento. Sob $10^{\circ} \mathrm{C}$, a inibição da ação do etileno inibe não apenas a síntese de etileno (Figura 1A), mas também reduz as demais alterações decorrentes do 

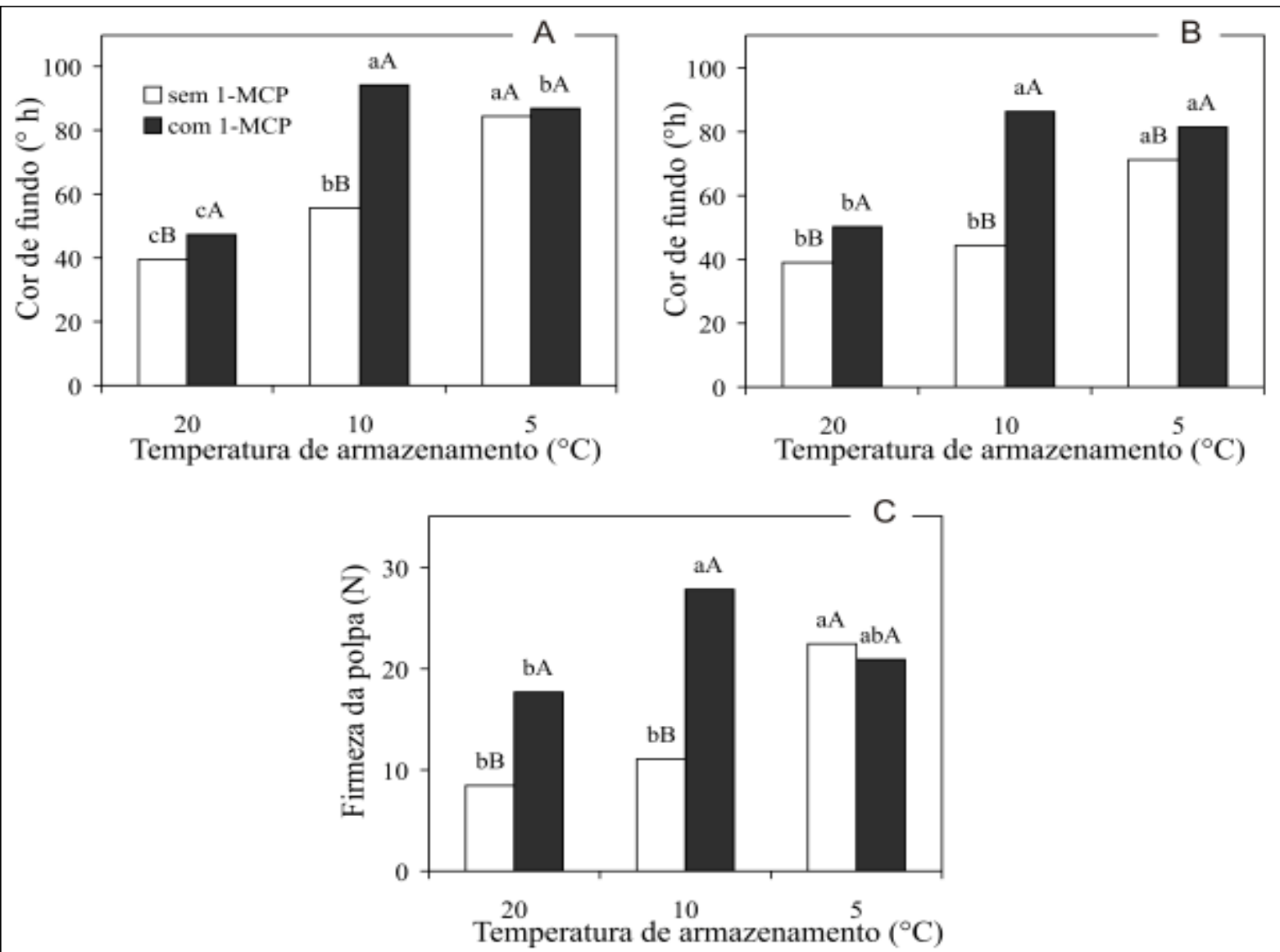

Figura 2 - Efeito da aplicação de 1-MCP na concentração de $1 \mu \mathrm{L} \mathrm{L}^{-1}$ de ar da câmara e da temperatura de armazenamento sobre a cor de fundo da epiderme após um (A) e quatro dias de vida de prateleira (B) e sobre a firmeza da polpa (C) de tomates da cultivar 'Monte Carlo' após 14 dias de armazenamento e mais quatro dias de vida de prateleira a $20^{\circ} \mathrm{C}$. Santa Maria, RS, Brasil. Letras minúsculas representam a comparação entre as médias das temperaturas de armazenamento, e letras maiúsculas indicam a comparação entre a aplicação ou não de 1-MCP, para uma mesma temperatura, pelo teste de Duncan $(\mathrm{P} \leq 0,05)$.

amadurecimento, como o desenvolvimento de cor vermelha (Figura 1D) e a degradação da cor verde (Figuras 2A e B) e da firmeza da polpa (Figura 3C). Por outro lado, as alterações que ocorrem a $5{ }^{\circ} \mathrm{C}$ desencadeiam uma elevada síntese de etileno pósarmazenamento (Figura 1A), a qual não se reflete, todavia, no desenvolvimento da maturação. Esse resultado poderia indicar que o dano pelo frio resulta na perda de sensibilidade dos frutos ao etileno e, consequentemente, num padrão anormal de amadurecimento. Apesar do leve aumento no escurecimento da casca nos frutos tratados com 1-MCP e mantidos a $5^{\circ} \mathrm{C}$ (Figura 1C), os resultados deste trabalho não permitem demonstrar claramente se o etileno desempenha um papel na tolerância de tomates a baixas temperaturas.

\section{CONCLUSÕES}

A inibição da ação do etileno resulta em dois padrões distintos de amadurecimento em tomates não longa vida, dependendo da temperatura de armazenamento. Sob $5^{\circ} \mathrm{C}$, há o desenvolvimento de danos pelo frio, que resulta em elevada produção de etileno sem, contudo, permitir alterações significativas no amadurecimento dos frutos, indicando que sob essa temperatura os frutos perdem a sensibilidade ao etileno. No entanto, sob temperaturas acima do limite de danos, a aplicação de 1-MCP reduz a síntese de etileno e o amadurecimento, sendo a duração desse efeito maior a $10^{\circ} \mathrm{C}$ do que a $20^{\circ} \mathrm{C}$.

Em relação à manutenção da qualidade póscolheita, os tomates não longa vida da cultivar 'Monte Carlo' mantêm a qualidade por até 14 dias com o 

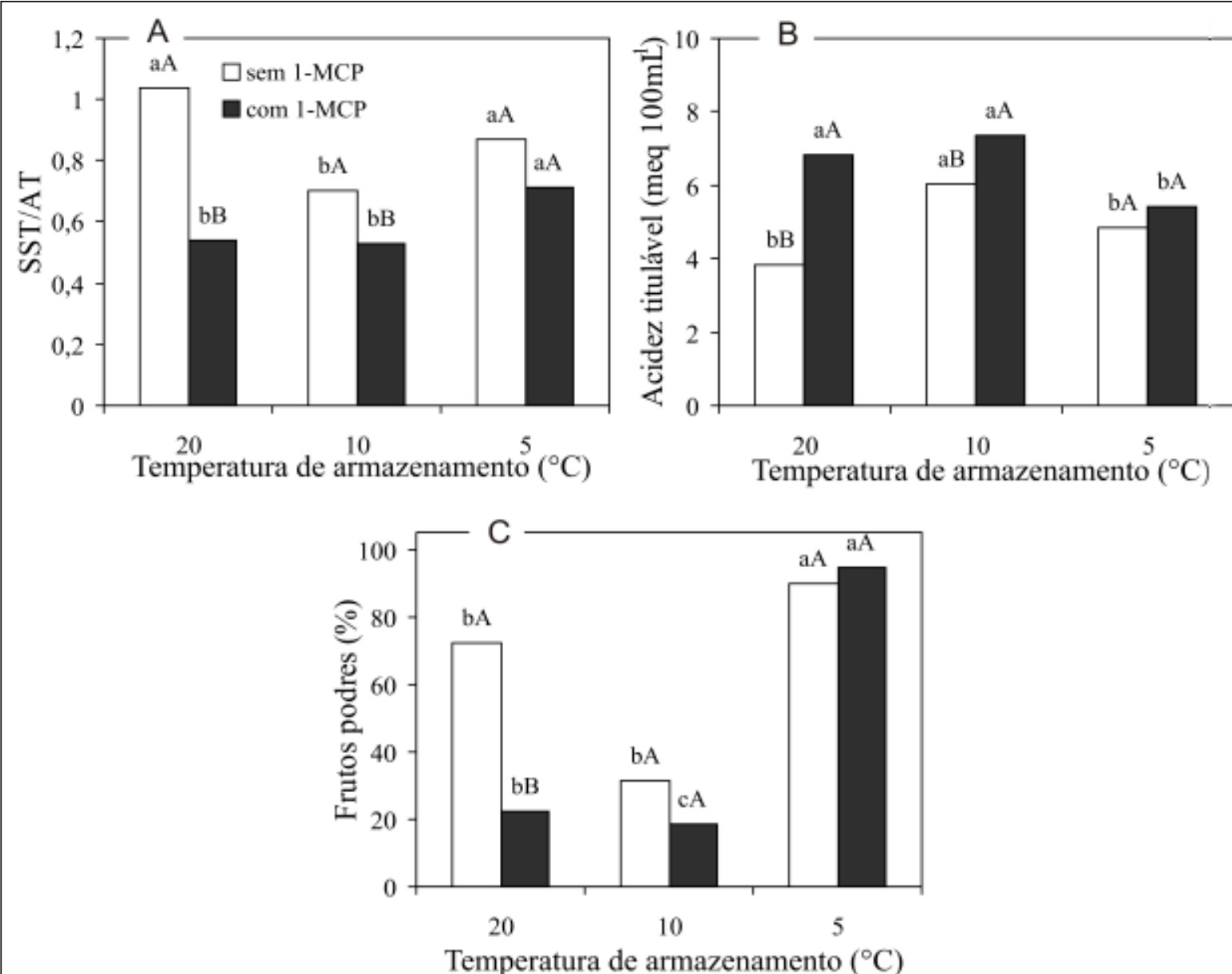

Figura 3 - Efeito da aplicação de 1-MCP e da temperatura de armazenamento sobre a relação SST/AT (A), a acidez titulável (B) e a ocorrência de podridões (C) em tomates da cultivar 'Monte Carlo' após 14 dias de armazenamento e mais quatro dias de vida de prateleira a $20^{\circ} \mathrm{C}$. Santa Maria, RS, Brasil. Letras minúsculas representam a comparação entre as médias das temperaturas de armazenamento, e as letras maiúsculas indicam a comparação entre a aplicação ou não de 1-MCP, para uma mesma temperatura, pelo teste de Duncan $(\mathrm{P} \leq 0,05)$.

armazenamento a $10^{\circ} \mathrm{C}$ ou com a aplicação de 1-MCP a $20^{\circ} \mathrm{C}$. Todavia, ainda precisa ser elucidado se o armazenamento de frutos tratados com 1-MCP e armazenados a $10^{\circ} \mathrm{C}$ frutos por períodos maiores que 14 dias permitiria superar a inibição do amadurecimento provocada pela aplicação de 1-MCP.

\section{REFERÊNCIAS}

ALEXANDER, L.; GRIERSON, D. Ethylene biosynthesis and action in tomato: a model for climacteric fruit ripening. Journal of Experimental Botany, v.53, p.2039-2055, 2002. Disponível em: http://jxb.oxfordjournals.org/cgi/content/full/ 53/377/2039. Doi: $10.1093 /$ jxb/erf072.

BEN-AMOR, M. et al. Inhibition of ethylene biosynthesis by antisense ACC oxidase RNA prevents chilling injury in Charentais cantaloupe melons. Plant, Cell and Environment, Oxford, v.22, p.1579-1586, 1999. Disponível em: http:// www3.interscience.wiley.com/cgi-bin/fulltext/119087579/ HTMLSTART. Acesso 17 fev. 2009. Doi: 10.1046/j.13653040.1999.00509.x.

BRANDT, S. et al. Lycopene content and colour of ripening tomatoes as affected by environmental conditions. Journal of the Science of Food and Agriculture, Hoboken, v.86, p.568572, 2005. Disponível em: http://www3.interscience.wiley.com/ journal/112188408/abstract. Acesso 17 fev. 2009. Doi: 10.1002/ jsfa.2390.

CIARDI, J.A. et al. Increased ethylene synthesis enhances chilling tolerance in tomato. Physiologia Plantarum, Copenhagen, v.01, n.2, p.333-340, 1997. Disponível em: http:/ /www3.interscience.wiley.com/cgi-bin/fulltext/119168722/ PDFSTART. Acesso 17 fev. 2009. Doi: 10.1111/j.13993054.1997.tb01005.x.

GUILLÉN, F. et al. Efficacy of 1-MCP treatment in tomato fruit: 1. Duration and concentration of 1-MCP treatment to gain an effective delay of postharvest ripening. Postharvest 
Biology and Technology, Amsterdam, v.43, n.1, p.23-27, 2007. Disponível em: http://www.sciencedirect.com/ s cience? ob = Article URL\&_udi=B 6 T B J $4 \mathrm{KSD} 83 \mathrm{~S} 1$ \&_user $=687358 \&$ rdoc $=1 \&$ fmt $=$ \&_orig $=$ search\&_ 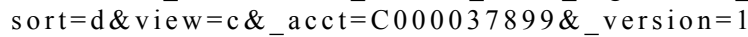 \& u r l Versio $\mathrm{n}=0 \&$ us e r i d $=68735$ $8 \& \mathrm{md} 5=\mathrm{b} 14 \mathrm{ac} 11 \mathrm{c} 4 \mathrm{e} 065809621 \mathrm{db} 82489 \mathrm{~b} 8 \mathrm{~d} 9 \mathrm{f} 3$. Acesso 17 fev. 2009. Doi: 10.1016/j.postharvbio.2006.07.004.

HOBSON, G.; GRIERSON, D. Tomato. In: SEYMOUR, G. et al. (Eds.). Biochemistry of fruit ripening. London: Chapman and Hall, 1993. p.405-442.

HOEBERICHTS, F. et al. Ethylene perception is required for the expression of tomato ripening-related genes and associated physiological changes even at advanced stages of ripening. Postharvest Biology and Technology, Amsterdam, v.26, p.125-133, 2002. Disponível em: http://www.sciencedirect.com/ science?_ob=ArticleURL\&_udi=B6TBJ-454T84X$1 \&$ u s e r $=687358 \&$ c o ver Dat e $=09 \% 2 \mathrm{~F} 0$ $1 \% 2 \overline{\mathrm{F}} 2002 \&$ rdoc $=3 \&$ fmt $=$ high\&_orig=browse\&_srch $=$ docinfor $\% 23$ toc \% $235144 \% 232002 \% 23999739997$ $\% 23334154 \% 23$ FLA \%23 display\%23 Volume)\&_cdi= $5144 \&$ sort $=$ d\&_docanchor $=\&$ ct $=14 \&$ acct $=\mathrm{C} 0000$ 37899 \&_version $=1 \&$ \& ur 1 Vers i o n $=0 \&$ \& u serid $=6873 \overline{5} 8 \& \mathrm{md} 5=\mathrm{aabfa} 3730 \overline{8} 405 \mathrm{ccf} 5 \mathrm{f} 5 \mathrm{~d} 8511 \mathrm{f} 798 \mathrm{fa} \overline{7} \mathrm{~b}$. Acesso 17 fev. 2009. Doi: 10.1016/S0925-5214(02)00012-1.

JIMENEZ, A. et al. Changes in oxidative processes and components of the antioxidant system during tomato fruit ripening. Planta, Bonn, v.214, n.5, p.751-758, 2002. Disponível em: http://www.springerlink.com/content/ d7ydefg1a901vqdx/fulltext.pdf. Acesso 17 fev. 2009. Doi: $10.1007 / \mathrm{s} 004250100667$

LAFUENTE, M.T. et al. Phenylalanine ammonialyase as related to ethylene in the development of chilling symptoms during cold storage of citrus fruits. Journal of Agricultural and Food Chemistry, Washington, v.49, p.6020-6025, 2001. Disponível em: http://pubs.acs.org/doi/full/10.1021/ jf010790b?cookieSet=1. Acesso 17 fev. 2009. Doi: 10.1021/ jf010790b.

MALACRIDA, C. et al. Postharvest chilling induces oxidative stress response in the dwarf tomato cultivar Micro-Tom. Physiologia Plantarum, Copenhagen, v.127, n.1, p.10-18, 2006. Disponível em: http://www3.interscience.wiley.com/cgibin/fulltext/118601657/HTMLSTART. Acesso 17 fev. 2009. Doi: $10.1111 /$ j.1399-3054.2005.00636.x.

MONTILLET, J.-L. et al. Fatty acid hydroperoxides and $\mathrm{H} \mathrm{O}$ in the execution of hypersensitive cell death in tobacco leaves. Plant Physiology, Rockville, v.138, p.1516-1526, 2005. Disponível em: http://www.pubmedcentral.nih.gov/ articlerender.fcgi? artid=1176422. Acesso 17 fev. 2009. Doi: 10.1104/pp.105.059907.

MORRIS, L.L. Chilling injury of horticultural crop: an overview. HortScience, Alexandria, v.17, p.161-162, 1982.

ROSE, J.K.C. et al. Expression of a divergent expansin gene is fruit-specific and ripening-regulated. Proceedings of the
National Academy of Sciences of the United States of America, Washington, v.94, p.5955-5960, 1997. Disponível em: http://www.bio.psu.edu/Expansins/reprints/RosePNAS1997.pdf. Acesso 17 fev. 2009.

SALTVEIT, M.K. Chilling injury is reduced in cucumber and rice seedlings and in tomato pericarp discs by heat-shocks applied after chilling. Postharvest Biology and Technology, Amsterdam, v.21, p.169-177, 2001. Disponível em: http:// w w w. s c i e n c e d i r e c t . c o m / science?_ob=ArticleURL\&_udi=B6TBJ-423J9V4$3 \&$ u s e r $=687358 \&$ \& c o ver D a t e $=01 \% 2$ F 0 $1 \% 2 \mathrm{~F} 2001 \&$ rdoc $=3 \&$ fmt $=$ high\&_orig $=$ browse\&_srch $=$ docinfo(\%23toc\%235144\%232001\%23999789997\%23224113 $\% 23$ FLA $\% 23$ display $\% 23$ Volume)\&_cdi $=5144 \&$ \& sort $=$ d\&_docanchor $=\&_{-}$c t $t=12 \&$ _ a c c t $=$ C 00003789 $9 \&^{-}$version $=1 \&^{-}$ur 1 Version $=0 \& \quad$ userid $=68 \overline{7} 358 \& \mathrm{md} 5=830 \mathrm{f} 7 \overline{4} \mathrm{cb} 98 \mathrm{~d} 57 \mathrm{e} 3 \mathrm{db} 65 \mathrm{~b} 26 \mathrm{e} 0 \overline{2} \mathrm{a} 6121 \mathrm{a} 3$. Acesso 17 fev. 2009. Doi: 10.1016/S0925-5214(00)00132-0.

SALTVEIT, M.K. Influence of heat shocks in the kinetics of chilling-induced ion leakage from tomato pericarp discs. Postharvest Biology and Technology, Amsterdam, v.36, p.87-92, 2005. Disponível em: http http:// w w w. s c i e $n$ c e d i r e c t r c o m / science? ob=ArticleURL\& udi=B6TBJ-4FFN4VM$1 \&$ u ser $=687358 \&$ _cover Date $=04 \% 2$ F $30 \% 2 \mathrm{~F}$ $2005 \&$ _rdoc $=12 \&$ fmt $=$ high\&_orig $=$ browse\&_srch $=$ docinfo(\%23toc\%235144\%232005\%23999639998\%23585314\%23F LA\%23display\%23Volume)\&_cdi $=5144 \&$ \& sort $=d \&$ docanc hor $=\&_{-} \mathrm{ct}=14 \&_{-}$ac ct $=\mathrm{C} 000037899 \&_{-}$version $=1$ \&_ur i versio n $=0$ \&_u se rid $=\overline{6} 87358 \&$ $\mathrm{md} 5=\mathrm{e} 7 \mathrm{a} 1 \mathrm{bd} 29 \mathrm{~d} 123 \mathrm{~d} 0967 \mathrm{e} 0 \mathrm{a} 30 \mathrm{~b} 123 \mathrm{~b} 2 \mathrm{a} 4 \mathrm{a} 3$. Acesso $17 \mathrm{fev}$. 2009. Doi: $10.1016 /$ j.postharvbio.2004.10.007.

SITRIT, Y.; BENNETT, A.B. Regulation of tomato fruit polygalacturonase mRNA accumulation by ethylene: a reexamination. Plant Physiology, Rockville, v.116, p.11451150, 1998. Disponível em: http://www.plantphysiol.org/cgi/ content/full/116/3/1145. Acesso 17 fev. 2009.

TIEMAN, D.M. et al. The tomato ethylene receptors NR and LeETR4 are negative regulators of ethylene response and exhibit functional compensation within a multigene family. Proceedings of the National Academy of Sciences of the United States of America, Washington, v.97, p.5663-5668, 2000. Disponível em: http://www.pnas.org/content/97/10/ 5663.full. Acesso 17 fev. 2009.

WILLS, R.B.H., KU, V.V.V. Use of 1-MCP to extend the time to ripen of green tomatoes and postharvest life of ripe tomatoes. Postharvest Biology and Technology, Amsterdam, v.26, p.85-90, 2002. Disponível em: http://www.sciencedirect.com/ science?_ob=ArticleURL\&_udi=B6TBJ-44NM1N5$3 \&$ u s e r $=687358 \&$ c o ver Date $=08 \% 2$ F 31 $\% 2 \mathrm{~F} 2002 \&$ rdoc $=8 \&$ fmt $=$ high \&_orig $=$ browse \&_srch $=$ docinfo(\%23toc\%235144\%232002\%23999739998\%23324600\%2

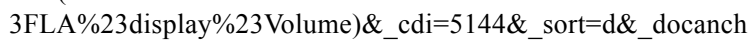
or $=\&$ \& $\mathrm{t}=13 \&$ \& a c ct $=\mathrm{C} 000037899 \&$ \& ersion $=1$ \&_u r 1 Versio $n=0 \&$ u se rid $=687358 \&$ $\mathrm{md} 5=\mathrm{ba} 7 \mathrm{~d} 25 \mathrm{eb} 5 \mathrm{~d} 757364443 \mathrm{f} 67537605 \mathrm{~b} 8 \mathrm{c} 0$. Acesso $17 \mathrm{fev}$. 2009. Doi: $10.1016 / \mathrm{S} 0925-5214(01) 00201-0$. 